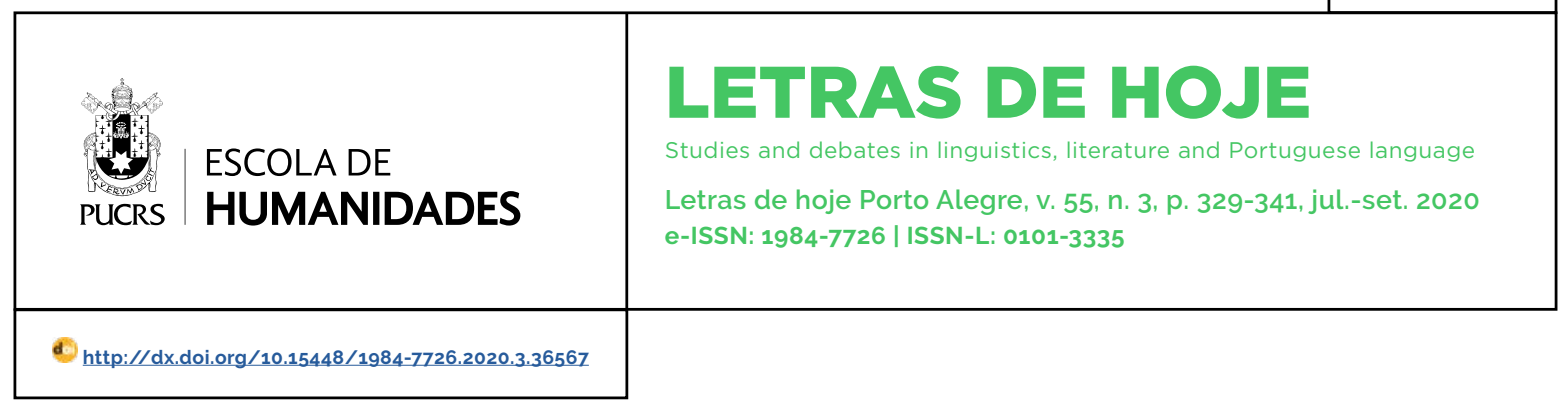

TEMÁTICA LIVRE

\title{
Fenômenos representativos de adolescentes em contexto socioeducativo sobre escolarização, abandono escolar e aulas de língua materna
}

\author{
Representative phenomena of adolescents in socio-educational context about \\ schooling, dropping out and mother tongue classes \\ Fenómenos representativos de adolescentes en contexto socioeducativo sobre \\ escolaridad, abandono escolar y clases de lengua materna
}

\section{Sabrina Cecilia Moraes Bastos $^{1}$ \\ orcid.org/0000-0002-9810-5745 \\ scmbastos@gmail.com}

\section{Cátia de Azevedo}

Fronza $^{1}$

orcid.org/0000-0002-7777-7884 catiafronza@gmail.com

Recebido em: 30/12/2019

Aprovado em: 16/10/2020

Publicado em: 17/12/2020

\section{(c) (1)}

Artigo está licenciado sob forma de uma licença Creative Commons Atribuição 4.0 Internacional.
Resumo: Este artigo resulta de uma pesquisa de mestrado e visa apresentar um recorte de dados que demonstra as construções de realidade de adolescentes em medida socioeducativa de internação, em relação à escolarização, abandono escolar e às aulas de lingua materna. O estudo foi realizado com base em uma pesquisa qualitativa de cunho etnográfico e exploratória, no campo da Linguística Aplicada, com cinco turmas dos anos finais do ensino fundamental, em uma escola inserida em uma unidade de atendimento socioeducativo. A base teórica fundamenta-se na Teoria das Representações Sociais, Identidade, Diferença e estudos sobre a educação de adolescentes em conflito com a lei. Os resultados demonstram que os jovens constroem dialogicamente mundos de vida de exclusão e, como conclusão, observamos que o espaço de escolarização em contexto socioeducativo é um espaço importante, que tem potencial para (re)significar as perspectivas de vida desses jovens. Palavras-chave: Letramentos. Representações Sociais. Socioeducação. Adolescentes em conflito com a lei.

Abstract: This article is the result of a master's research and aims to present a data collection that demonstrates the constructions of reality of adolescents in socio-educational measure, in relation to schooling, dropping out and mother tongue classes. The theoretical basis is based on the Theory of Social Representations, Identity, Difference and studies on the education of adolescents in conflict with the law. The results show that adolescents dialogically construct exclusionary life worlds and, as a conclusion, we observe that the schooling space in a socio-educational context is an important space that has the potential to (re)signify the life perspectives of these adolescents. Keywords: Literacy. Social representations. Socio-educational confinement. Adolescents in conflict with the law.

Resumen: Este artículo resulta de una investigación de maestria y tiene como objetivo presentar un fragmento de datos que demuestra las construcciones de realidad de adolescentes en medida socioeducativa de internación, en relación con la escolarización, el abandono escolar y las clases de lengua materna. El estudio fue realizado con base en una investigación cualitativa de naturaleza etnográfica y exploratoria, en el campo de la Lingüística Aplicada, con cinco clases de los años finales de la enseñanza primaria, en una escuela insertada en una unidad de servicio socioeducativo. La base teórica se fundamenta em la Teoria de las Representaciones Sociales, Identidad, Diferencia y estudios acerca de la educación de adolescentes en conflicto con la ley. Los resultados demuestran que los jóvenes construyen dialógicamente mundos de vida de exclusión y, como conclusión, observamos que el espacio de escolarización en contexto socioeducativo es un espacio importante, que tiene potencial para (re)significar las perspectivas de vida de estos jóvenes.

Palabras clave: Letramentos. Representaciones Sociales. Socioeducación. Adolescentes en conflicto con la ley. 


\section{Introdução}

O ensino de adolescentes que estão em cumprimento de medida socioeducativa de internação faz parte da complexidade dos processos de escolarização dos anos finais do ensino fundamental. O contexto das medidas socioeducativas é estabelecido pelo Estatuto da Criança e do Adolescente (ECA), Lei 8.069/1990, e pelo Sistema Nacional de Atendimento Socioeducativo (Sinase), Lei 12.594/2012, que regulamenta a execução das medidas socioeducativas previstas no ECA.

De acordo com a legislação, a escolarização é um direito dos adolescentes privados de liberdade, sendo educação e escolarização eixos estratégicos dos parâmetros de ação socioeducativa (SINASE, 2006, p. 54). A denominação de medidas socioeducativas considera a condição peculiar de pessoa em desenvolvimento do adolescente, em atenção às definições constitucionais, "em lugar de penas, atribui à punição um caráter predominantemente educativo". (CRAIDY, 2012, p. 49).

A educação de adolescentes em conflito com a lei, mais do que um direito, é uma possibilidade de desenvolvimento pessoal, que pode auxiliar na inclusão desses jovens (PADOVANI; RISTUM, 2016). Com base em uma visão mais abrangente, Volpi (2019) defende a ideia de que os modelos assistencial-caritativo e correcional-repressivo devem ser superados, pois os problemas que 0 pais tem com a infância e com a adolescência não podem ser resolvidos nessa perspectiva. É fundamental que o adulto tenha uma visão pedagógica em sua tarefa na relação com os adolescentes.

Assim sendo, antes de serem tomados como um problema social, os adolescentes em contexto de internação socioeducativa devem ser considerados uma prioridade social de âmbito nacional, conforme indicam Bozza (2012) e Comerlato (2015). De acordo com Volpi (2019, p. 201), "o delito não é algo que está no sujeito; ele está na sociedade, ele faz parte de uma dinâmica social".

Cabe destacar que praticamente não existem estudos anteriores, no campo da Linguística Aplicada (LA), voltados aos letramentos de adolescentes em privação de liberdade. Considera-se que este estudo contribui para os estudos em LA, em uma perspectiva de linguagem e inclusão, pois possibilita um conhecimento prévio dos alunos, caracterizados como adolescentes privados de liberdade, em suas construções de realidade, assim como o conhecimento do contexto de escolarização em espaço socioeducativo.

Este estudo se situa entre a interdisciplinaridade da Linguística Aplicada (CELANI, 1992, p. 4) e a transdisciplinaridade da Teoria das Representações Sociais (JODELET, 2016, p. 1262) para compreender aspectos da vida dos adolescentes expressos e materializados na e pela linguagem.

O objetivo deste artigo é apresentar um relato da pesquisa de Bastos (2019), por meio de um recorte de dados que demonstra as construções de realidade de adolescentes em medida socioeducativa de internação, em relação às aulas de lingua materna, escolarização e abandono escolar no contexto de escola da rede pública estadual inserida em uma grande unidade de internação socioeducativa no Rio Grande do Sul.

Os dados apresentados neste estudo foram gerados com base em uma pesquisa qualitativa de cunho etnográfico e exploratório (PAIVA, 2019). $O$ interesse pela pesquisa resulta das vivências de Bastos, que foi professora de Lingua Portuguesa, nos anos finais do ensino fundamental, na escola onde a pesquisa foi desenvolvida.

Para guiarmos nossa discussão sobre os fenômenos representativos de adolescentes privados de liberdade sobre escolarização, abandono escolar e as aulas de língua materna, exporemos, a seguir, alguns pressupostos teóricos relativos à Teoria das Representações Sociais (JODELET, 1993; 2017; 2018), Identidade e Diferença (HALL, 1997: SILVA, 2000) e perspectivas educacionais de adolescentes em conflito com a lei (CRAIDY, 2012; 2015).

\section{Teoria das Representações Sociais}

As representações sociais são forjadas na interação e em contato com os discursos em circulação no espaço público. Além disso, estão inscritas na linguagem e nas práticas e funcionam como linguagem em razão de sua função simbólica e dos referentes que elas fornecem para codificar e categorizar o que povoa o universo 
de vida (JODELET, 2018, p. 429). Desse modo, "o estudo dos processos e dos produtos, pelos quais os individuos e os grupos constroem e interpretam 'seu mundo de vida', permite a integração da subjetividade com as dimensões social, cultural e histórica". (JODELET, 2018, p. 426).

Neste estudo, vinculamo-nos à noção de fenômenos representativos (JODELET, 2018) como elementos atuantes na vida social, relacionados à dinâmica da força social, afastando a abordagem teórica de percepções essencialmente intelectuais de representação e voltando-se para o caráter dinâmico dos fenômenos representativos.

Jodelet (2018, p. 430) explica que existem diversas vantagens relativas à adoção da perspectiva dos fenômenos representativos, uma vez que esse deslocamento permite "se vincular àquilo que é observável ou às construções intelectuais identificadas pela análise textual de enunciados públicos, de documentos publicados ou registrados durante investigações", sem precisar optar por uma das diversas definições da noção de representação. Além disso, a adoção da perspectiva dos fenômenos representativos favorece que não ocorra um fechamento em alguma definição substancial da noção de representação social, pois um fechamento em definições substanciais pode restringir a percepção sobre as realidades estudadas.

As representações sociais são, ao mesmo tempo, produto e processo de uma atividade de "apropriação da realidade exterior ao pensamento e da elaboração psicológica e social da realidade". (JODELET, 1993, p. 5). Assim sendo, a experiência comporta uma dimensão cognitiva, porque favorece "a experimentação do mundo sobre o mundo e concorre para a construção da realidade, segundo categorias que são socialmente dadas". (JODELET, 2017, p. 438).

Essa experiência constitui o sentido que o sujeito atribui a fatos, situações, objetos e pessoas que com ele convivem e seu mundo de vida, relacionado ao mundo comum, comunicado por intermédio da linguagem. Portanto, a experiência é um conceito de ordem social e é socialmente construida. (JODELET, 2017, p. 438).

Os fenômenos representativos são portadores de um status epistemológico e contêm valor de verdade e valor de realidade. Por isso, tomamos o conhecimento de senso comum de adolescentes em medida socioeducativa de internação como forma de registro e instrumento de reflexão, visando a contribuir com estudos e iniciativas que thes gerem mudanças.

A fim de compreender os fenômenos representativos dos adolescentes, na seção seguinte, traremos uma breve inter-relação teórica sobre adolescentes em conflito com a lei, educação e linguagem.

\section{Educação de adolescentes em conflito com a lei, linguagem, identidade e diferença}

"A educação é o espaço da palavra, da interlocução e do diálogo. Se não for interlocução, a palavra será imposição". (CRAIDY, 2015, p. 74). A educação se configura por intermédio de relações dialógicas, porque é um espaço essencialmente de linguagem. Essas relações dialógicas constituem todo discurso, pois, como propriedade de linguagem, estabelecem inter-relações com outros discursos e com o discurso do outro. (FLORES et al., 2009).

Nesse sentido, segundo Faraco (2009, p. 84), o sujeito dialógico se constitui em uma realidade linguística de "um mundo de vozes sociais em múltiplas relações dialógicas - relações de aceitação e recusa, de convergência e divergência, de harmonia e de conflitos, de intersecções e de hibridizações". Assim, em uma interação socioideológica, constitui-se discursivamente, "assimilando vozes sociais e, ao mesmo tempo, suas inter-relações dialógicas". (FARACO, 2009, p. 84).

Faraco (2009, p. 84) menciona um pensamento de Bakhtin sobre o qual afirma que "nossas palavras não são tomadas do dicionário, mas do lábio dos outros". Sob essa perspectiva, observamos que as identidades são ocasionadas por um conjunto especial de circunstâncias, sentimentos e experiências exclusivamente nossas. Além disso, são construidas no interior da representação, por meio da cultura. (HALL, 1997). As diferentes posições do sujeito, que formam as identidades também caracterizam a "diferença". (HALL, 2006). 
Nessa relação entre identidade e diferença, Silva (2000) explica que identidade e diferença são produzidas no contexto das relações culturais e sociais. Portanto, são criadas por meio de atos de linguagem. Não são "fatos da vida", já que são nomeadas. Identidade e diferença se instituem por meio de atos de fala.

Santos (1999, p. 2-3) explica que a desigualdade é um fenômeno socioeconômico, e a exclusão é um fenômeno social e cultural, resultante de um processo histórico, com o qual uma cultura, por meio de um "discurso de verdade", cria a diferença, na figura de um interdito, rejeitando-o. O processo de rejeição estabelece "um limite para além do qual só há transgressão, um lugar que atira para outro lugar, a heterotopia, todos os grupos sociais que são atingidos pelo interdito social, sejam eles a loucura, o "crime"2, a delinquência ou a orientação sexual".

A exclusão escolar, motivada por fatores internos e externos à escola (STECANELA, 2008), as dificuldades de integração na escola e as múltiplas reprovações são caminhos para o ato infracional. Craidy (2015, p. 80) observa que os jovens que não estudam nem trabalham ("nem-nem") vagam pelas ruas da periferia sem perspectiva de inserção social e frequentemente são recrutados por facções criminosas, lideradas por adultos. Trata-se de um recrutamento que leva os adolescentes à integração em universo criminoso que lhes "confere a importância e o sentimento de ser alguém, para os que não tinham referências nem esperanças. As vantagens materiais também são importantes neste recrutamento, mas podem ser menos significativas do que os sentimentos de 'pertencer' e de 'ser' alguém" (CRAIDY, 2015, p. 80).

$\mathrm{O}$ adolescente, tomado como sujeito de direitos, pessoa em desenvolvimento, com múltiplas potencialidades e com direito à palavra (CRAIDY, 2012), para exercer sua cidadania, precisa apropriar-se da leitura e da escrita como práticas sociais. Comerlato (2015, p. 91) chama atenção para o fato de que "a baixa escolaridade desses jovens também é um fator de vulnerabilidade social, o que leva à exclusão em uma sociedade urbana, complexa, competitiva que valoriza essencialmente os conhecimentos formais".

O aprendizado da leitura e da escrita configura-se na exigência do domínio de uma norma padrão, implicando a "simbolização do código escrito, das regras escolares, das exigências, às vezes absurdas, do discurso pedagógico; enfim, é como se o aprendiz entrasse em outro país, onde se fala outra língua e onde há regras de comportamento diferentes". (TFOUNI; PEREIRA; ASSOLINI, 2018, p. 19).

Cultura, ensino e aprendizagem têm uma relação dialética. Professores e escola, ao escolherem determinado tópico de estudo da linguagem ou modelo curricular, por exemplo, "expressam sua expectativas sobre o que é para eles significativo na ação de ensinar e aprender". (OLIVEIRA, 2010, p. 128). Assim sendo, Oliveira (2010) recomenda que se olhe para a sala de aula como um espaço de cultura, para que se possa perceber a importância de uma pedagogia sensivel às diferenças, pois considera que as práticas de letramento constituem e são constituidas pela cultura.

\section{Metodologia}

Os dados apresentados a seguir foram gerados pela pesquisa de mestrado de Bastos (2019), desenvolvida por meio de metodologia qualitativa de cunho etnográfico (SILVERMAN, 2009; FLICK, 2009) e exploratória (PAIVA, 2019). O objetivo do estudo de Bastos (2019) foi analisar os fenômenos representativos (JODELET, 2018) expressos por adolescentes em cumprimento de medida socioeducativa de internação, cursando os anos finais do ensino fundamental, como forma de evidenciar as construções de realidade elaboradas pelos adolescentes em seus mundos de vida.

Como instrumento para pesquisa exploratória, foi utilizada a entrevista qualitativa, desenvolvida por meio de rodas de conversa, guiadas com base em tópicos-guia. (GASKEL, 2003, p. 66). Os dados de pesquisa foram gerados, no horário da

2 Embora o ECA, Lei 8.060/1990, estabeleça que os jovens menores de 18 anos são penalmente inimputáveis, chamando, no Art. 103. de ato infracional a conduta caracterizada como crime ou contravenção penal, neste verbete empregamos as palavras crime e criminoso, porque são termos recorrentes na fala dos adolescentes. 
aula de Língua Portuguesa, por meio de rodas de conversa com cinco turmas de adolescentes dos anos finais do ensino fundamental, três turmas em uma unidade masculina e duas em uma unidade feminina, totalizando 23 participantes. As interações foram gravadas em vídeo, e as falas foram transcritas ortograficamente, mas com registro o mais aproximado possivel de sua pronúncia.

O projeto de pesquisa do qual resulta este artigo foi submetido ao Comitê de Ética em Pesquisa da Universidade, conforme CAAE n॰ 80658417.8.0000.5344. Parecer $n^{\circ} 2.467 .579$ e foi aprovado.

No decorrer da geração de dados, tomamos todos os cuidados éticos, observando os preceitos legais estabelecidos nos artigos 17 e 94, inciso IV, do Estatuto da Criança e do Adolescente (ECA), Lei n 8.069/1990, que garantem o direito ao respeito, a preservação da imagem, da identidade e da dignidade dos adolescentes. (BRASIL, 1990).

Também cumprimos com o que preconizam as Resoluções n 466/2012, que aprova as diretrizes e normas regulamentadoras de pesquisas envolvendo seres humanos, e n 510/2016, que regulamenta as pesquisas com procedimentos metodológicos que envolvem a utilização de dados diretamente obtidos com os participantes ou de informações identificáveis.

Para compreender melhor o cenário da pesquisa, apresentamos a escola-alvo, os participantes, as considerações éticas e o processo de geração de dados.

\section{O espaço de pesquisa}

A pesquisa foi desenvolvida em uma escola da Rede Pública Estadual, que presta atendimento escolar de Ensino Fundamental e Médio e Ensino de Jovens e Adultos (EJA), exclusivamente a adolescentes que estão em cumprimento de medida socioeducativa de internação. Esses jovens são oriundos da capital, região metropolitana e de alguns centros de atendimento socioeducativos do interior, cuja transferência ocorre conforme demanda das unidades de internação.

A escola está inserida no espaço de um complexo de internação juvenil e não é administrativamente subordinada à instituição de atendimento socioeducativo. Sua mantenedora é a Secretaria Estadual de Educação. A Escola tem 18 anos de funcionamento, atende a 72 turmas entre ensino fundamental e médio e tem um efetivo de 66 professores.

As salas de aula ficam no interior dos Centros de Atendimento Socioeducativo (CASEs). A escola atende a quatro CASEs situados no complexo de internação juvenil. Cada ala do Centro de Atendimento Socioeducativo (CASE) tem em média quatro salas de aula. No horário das aulas, os alunos saem dos dormitórios, chamados internamente de "bretes", e são conduzidos pelos agentes de atendimento socioeducativo até as salas de aula. Os dormitórios são no andar de cima, e as salas de aula ficam no andar de baixo.

Durante as aulas, os alunos são monitorados por circuito interno de televisão com câmeras instaladas dentro das salas e por agentes posicionados à porta da sala de aula. Os professores se deslocam da sede administrativa da escola para o interior dos CASEs, onde ministram suas aulas, vestindo um jaleco ${ }^{3}$, item de uso obrigatório de professores e professoras no interior dos CASEs.

Os cadernos dos alunos das unidades masculinas não ficam com eles; na unidade feminina podem ficar com as alunas. A cada horário de aula, o professor pega uma bolsa com os cadernos da turma e um estojo com lápis, borracha e caneta, sempre contados de acordo com o número de cadernos da bolsa. Outros materiais, como apontador, régua, cola ou tesoura, são de responsabilidade e uso do professor. Ao final de cada aula, os materiais devem ser conferidos e guardados. Os alunos não podem ficar com nenhum tipo de material escolar para levar ao dormitório.

Os livros didáticos ficam numa salinha da escola, organizada com a finalidade de ser uma biblioteca. Caso algum professor queira utilizá-los, deve pegar o número necessário e levar para a sala de aula com os cadernos dos alunos e outros materiais de apoio que utilize. Muitas vezes, em

3 O uso do jaleco pelos/as professores/as justifica-se por ser um elemento de identificação do profissional que ingressa no interior das unidades de atendimento. Além disso, tem a função de encobrir as formas do corpo e detalhes da roupa dos professores e não chamar atenção dos alunos. 
vista do deslocamento entre a escola e o CASE e do peso que pode representar o volume de materiais a serem carregados, os professores optam por não utilizar os livros. Assim, as atividades ficam limitadas à exposição verbal e escrita no quadro, além de alguma atividade com folhas avulsas.

\section{Participantes da pesquisa}

Os participantes da pesquisa foram adolescentes do gênero masculino e feminino, na faixa etária de 14 a 18 anos, oriundos da capital e da região metropolitana, que estavam cumprindo medida socioeducativa de internação sem possibilidade de atividade externa (Ispae). Estavam cursando os anos finais do ensino fundamental na modalidade EJA e apresentavam grande defasagem idade-série. Haviam abandonado a escola há, em média, dois anos e retornaram pelo fato de a escolarização ser obrigatória durante o cumprimento de medida socioeducativa de internação.

Esses adolescentes estavam agrupados em cinco turmas multisseriadas, formadas por, no máximo, 10 alunos, com diferentes totalidades da EJA. Destaca-se que o quantitativo de alunos por turma pode variar para menos de 10, mas não para mais. Nem sempre as turmas contam com o total de 10 alunos, porque há grande rotatividade entre os internos, em vista de ingressos, transferências e desligamentos.

A turma 69 agrupava educandos das totalidades 5 e 6 , doravante T5 e T6, equivalentes a $8^{\circ}$ e $9^{\circ}$ anos. As turmas 70 e 73 contava com educandos das totalidades 3 e 4 , correspondendo aos $6^{\circ}$ e $7^{\circ}$ anos. As turmas 93 e 94, localizadas na unidade de internação feminina, contavam com as totalidades T3, T4, T5 e T6, ou seja, $6^{\circ}, 7^{\circ}$, $8^{\circ}$ e $9^{\circ}$ anos, agrupados em uma mesma turma.

\section{Processo de geração de dados}

No decorrer do seu trabalho docente, Bastos (2019) observou que havia certa resistência por parte dos adolescentes à realização das atividades propostas e também pôde observar que os conteúdos ensinados pareciam não fazer sentido a eles. Ao mesmo tempo em que o trabalho com atividades de Lingua Portuguesa parecia não dar certo, os adolescentes apresentavam muitas lacunas de aprendizagem e dificuldades nas práticas de leitura e escrita.

Em vista dessas percepções, originalmente, a Bastos (2019) planejou entrevistas em grupo com os adolescentes, para fazer uma sondagem quanto a suas percepções e expectativas sobre o ensino e a aprendizagem de Língua Portuguesa em relação as suas vivências escolares, visando a identificar possiveis caminhos para desenvolver um ensino mais adequado ao perfil dos alunos e ao contexto de ensino.

No decorrer das duas primeiras rodas de conversa, foi possivel observar que os tópicos sobre o ensino e a aprendizagem de Língua Portuguesa não foram produtivos. Emergiam das falas dos adolescentes informações relativas às suas vivências na rua e ao abandono escolar.

Assim, incorporamos às questões das rodas de conversa perguntas que possibilitaram a coesão entre a perspectiva de aprendizagem de lingua materna dos adolescentes, suas vivências escolares e o percurso entre o abandono escolar e as vivências na rua.

As novas questões exploradas nas rodas de conversa foram as seguintes: Por que na escola era chato e na rua era legal?; Alguém já reprovou na escola?; Na rua o que te impedia de frequentar a escola? (O que motivou o abando escolar?); Por que e para que vocês precisam de dinheiro?; E, quando tu começou a frequentar a "biquera4", era o que tu pensava? Como foi pra ti? Por que o "crime" te fez largar a escola? Quanto tempo antes de vir pra cá (unidade de internação) vocês ficaram fora da escola ou estavam frequentando a escola?

Bastos (2019) optou por explorar em seu estudo as manifestações que emergiram das falas dos adolescentes relativas à rua, ao abandono escolar e ao ensino e aprendizagem de língua materna. Essa escolha se justificou pelo fato de que os temas que emergiram nas falas dos adolescentes

\footnotetext{
4 A palavra "biqueira", na gíria dos adolescentes em cumprimento de medida socioeducativa de internação, significa o mesmo que "boca de fumo" ou, mais usualmente, "boca", ponto de tráfico, lugar onde drogas são vendidas.
} 
demonstravam aspectos subjacentes à condição daqueles alunos naquele espaço escolar.

Por restrições de espaço, neste estudo, apresentaremos um recorte de dados sobre ensino e aprendizagem de língua materna, escolarização e abandono escolar

\section{Dados em análise}

Neste tópico, passamos à análise dos dados a partir dos quais vamos discutir os fenômenos representativos sobre escolarização, abandono escolar e sobre as aulas de língua materna. Reiteramos que, em uma relação com o saber prático, deve-se se observar quem sabe, de onde sabe, como sabe e o efeito desse saber, conforme orienta Jodelet (1993), pois a representação traz a marca do sujeito e de sua atividade como conteúdo concreto do ato de pensar.

No processo de análise, buscamos evidenciar fenômenos representativos sobre escolarização, abandono escolar e aprendizagem de língua materna, observando as construções de realidade elaboradas pelos adolescentes. Os quadros apresentados a seguir se organizam com base na técnica de associação de ideias. (SPINK, 2013). Cabe enfatizar que, quando há referência aos adolescentes participantes, utilizam-se nomes fictícios, com o objetivo de preservar suas identidades. As falas foram transcritas de modo a representá-las com a maior fidelidade possivel.

\section{Fenômenos representativos relativos à escolarização e ao abandono escolar}

Neste tópico, apresentamos os fenômenos representativos dos adolescentes, que perpassam as relações entre a escola, o abandono escolar, o tempo fora da escola e o retorno à escola no contexto da medida socioeducativa de internação.

Ao serem questionados sobre quanto tempo haviam ficado fora da escola, os adolescentes expressaram também comentários relativos ao abandono escolar e ao reingresso à escola, em vista do cumprimento de medida socioeducativa de internação, conforme as falas dos adolescentes apresentadas no quadro a seguir.

Quadro 1 - Falas dos adolescentes sobre escola, abandono escolar, rua, tempos fora da escola e o retorno à escola no espaço de internação

\begin{tabular}{|c|c|c|}
\hline Escola X Abandono escolar X Rua & $\begin{array}{l}\text { Tempos fora } \\
\text { da escola }\end{array}$ & $\begin{array}{l}\text { Retorno à escola no espaço de } \\
\text { internação }\end{array}$ \\
\hline $\begin{array}{l}\text { Pedro: Não gostava de ir na escola, gostava de } \\
\text { ficar na rua. Não gostava da escola. Na escola, o } \\
\text { cara tinha que ficá quieto olhando pro quadro e } \\
\text { escrevendo. Na rua, eu fazia o que eu queria. }\end{array}$ & $\begin{array}{l}\text { João: Na rua } \\
\text { só estudei em } \\
\text { 2014. Faz } 4 \text { anos. }\end{array}$ & \multirow{2}{*}{$\begin{array}{l}\text { João: Na rua, o cara tava nem aí pro } \\
\text { colégio, aqui o cara estuda. Na rua, } \\
\text { eu já rodei umas cinco vezes na quin- } \\
\text { ta série e aqui (escola na internação) } \\
\text { o cara já avanço. }\end{array}$} \\
\hline \multirow{4}{*}{$\begin{array}{l}\text { Rafael: (16 anos): Eu parei de estuda né, dona, } \\
\text { desde os dez ano. Aí, no caso, eu não tava apren- } \\
\text { dendo nada, nada, eu bah! Mas, na real, a escola } \\
\text { não é pra mim, vô solta de vez e soltei e entrei } \\
\text { pra vida do "crime". [...] já andava no meio da va- } \\
\text { gabundagem, já ficava com os cupinxa na esqui- } \\
\text { na aí cada um cara já falava pro outro: "o cupinxa } \\
\text { tá estudando o cupinxa tá de loco! Quando vê o } \\
\text { cara pah, na real, nem vai estuda mais... já era, lar- } \\
\text { guei o estudo. }\end{array}$} & $\begin{array}{l}\text { Luiz: uns } 2 / 3 \\
\text { anos }\end{array}$ & \\
\hline & $\begin{array}{l}\text { Pedro: } 1 \text { ano e } \\
\text { meio }\end{array}$ & \multirow{3}{*}{$\begin{array}{l}\text { Luiz: Na rua só estudei em 2014. De- } \\
\text { pois que caí preso, desde 2015, só } \\
\text { estudei aqui (dentro da unidade de } \\
\text { internação) até a quarta fui normal, } \\
\text { passei pra quinta aqui (dentro da uni- } \\
\text { dade de internação). }\end{array}$} \\
\hline & Maria: 3 anos & \\
\hline & $\begin{array}{l}\text { Flávia: } 5 \text { ou } 6 \\
\text { meses }\end{array}$ & \\
\hline \multirow{3}{*}{$\begin{array}{l}\text { Miguel: Quando eu ia pra escola um dia os cara } \\
\text { que são meu contra iam lá pra me pega. Eles sa- } \\
\text { biam onde eu estudava, se eu fosse pro colégio } \\
\text { eles iam me pega lá. }\end{array}$} & Ana: 4 anos & \multirow{3}{*}{$\begin{array}{l}\text { Rafael: Ai, quando cai na fase, vi que } \\
\text { o bagulho não era assim, não sabia } \\
\text { nem lê nem escreve, fui aprendê, } \\
\text { né... aí foi que gostei de português, } \\
\text { matemática, várias eu gosto agora". }\end{array}$} \\
\hline & Luana: 2 anos & \\
\hline & $\begin{array}{l}\text { Mário: uns } 2 / 3 \\
\text { anos }\end{array}$ & \\
\hline
\end{tabular}




\begin{tabular}{|c|c|c|}
\hline Escola X Abandono escolar X Rua & $\begin{array}{l}\text { Tempos fora } \\
\text { da escola }\end{array}$ & $\begin{array}{l}\text { Retorno à escola no espaço de } \\
\text { internação }\end{array}$ \\
\hline $\begin{array}{l}\text { José: No caso, a rua significa ficar com os caras } \\
\text { fumando um baseado com os cupinxa do cara. } \\
\text { Na escola, tu fica lá tentando aprendê, não dá pra } \\
\text { conciliá o "crime" com o colégio. Aí o cara fica no } \\
\text { "crime". Não adianta o cara querê estudá e sê um } \\
\text { criminoso, isso nunca vai rolá. }\end{array}$ & José: 2 anos & \\
\hline $\begin{array}{l}\text { Luiz: Na rua, o cara corre atrás de dinheiro. No } \\
\text { colégio é bom, só que o cara não faz o negócio } \\
\text { com calma, porque o cara tá atrás de dinheiro. }\end{array}$ & $\begin{array}{l}\text { Laura: "Eu só } \\
\text { queria rua". }\end{array}$ & \\
\hline $\begin{array}{l}\text { Noé: "porque eu via os guri ali na frente na bique- } \\
\text { ra e eu ficava na volta ai me envolvi com os guris } \\
\text { dali e parei de estuda. }\end{array}$ & $\begin{array}{l}\text { Bianca: Eu fi- } \\
\text { quei } 2 \text { anos } \\
\text { sem frequenta. }\end{array}$ & \\
\hline $\begin{array}{l}\text { Diego: Eu saí da escola, não por causa do "crime". } \\
\text { Eu saí mesmo, porque eu ia e nunca aprendia } \\
\text { nada. Nunca saía da mesma série, eu via aquelas } \\
\text { criancinhas, me sentia mal, vinha, estudava cada } \\
\text { vez mais criança pequenininha; eu larguei da es- } \\
\text { cola, e como eu larguei da escola, o cara vai se } \\
\text { envolvendo na rua. }\end{array}$ & \multicolumn{2}{|c|}{$\begin{array}{l}\text { Leila: Quando eu vim pra cá, eu tava frequentando a } \\
\text { escola. }\end{array}$} \\
\hline \multicolumn{3}{|l|}{$\begin{array}{l}\text { Gabriel: Acho que uns dois anos, por causa que } \\
\text { eu entrei pro "crime", daí larguei a escola. }\end{array}$} \\
\hline & Diego: 5 anos & \\
\hline
\end{tabular}

Fonte: Bastos (2019, p. 79).

No quadro 2, apresentamos as falas dos adolescentes que nos permitem identificar fenômenos representativos relativos à escola em relação ao abandono escolar è̀ rua. Observamos, nas falas dos adolescentes, que escola, abandono escolar e rua estão interligados. Pedro e Luiz mencionam a rua como um espaço de liberdade, que adquire importância na organização de suas vidas, porque "é mais interessante" no aprendizado imediato de como obter recursos para sua sobrevivência. A rua se opõe à escola, pois, na escola, de acordo com Pedro, "o cara tinha que ficá quieto olhando pro quadro e escrevendo" ou, conforme afirma Luiz, mesmo sendo um bom lugar, "o cara não faz o negócio com calma, porque tá atrás de dinheiro".

Entretanto, após vivenciarem o abandono escolar, seguido do percurso pelas rotas do ato infracional, que, para esses adolescentes, culminou com a internação em medida socioeducativa, a percepção sobre a escola parece se modificar. João, Luiz e Rafael demonstram essa mudança de perspectiva ao falarem sobre o retorno à escola no espaço de internação. Rafael diz: "Ai, quando caí na fase, vi que o bagulho não era assim, não sabia nem lê nem escreve, fui aprendê, né... ai foi que gostei de português, matemática, várias eu gosto agora". Situação semelhante ocorreu com Luiz, quando afirma que "desde 2015 só estudei aqui (dentro da unidade de internação) até a quarta fui normal, passei pra quinta aqui (dentro da unidade de internação)"; e com João, no seguinte enunciado: "Na rua, eu já rodei umas cinco vezes na quinta série e aqui (escola na internação) o cara já avanço".

De modo mais objetivo, José argumenta que a escola é um lugar onde ele fica "tentando" aprender e opta pelo "crime", também observa que "não adianta o cara querê estudá e sê um criminoso, isso nunca vai rolá". Para José, as identidades de estudante e criminoso são contraditórias, cruzando-se e deslocando-se mutuamente, de modo inconciliável. A diferença expressa na fala do adolescente se constitui em um processo de 
inversão de valores, considerando que o lugar da exclusão, o "crime", tem mais valor do que a escola, como um lugar de aprendizado e desenvolvimento pessoal. A identidade de estudante, para José, tem atributos negativos e indesejáveis.

Ao afirmar, "Ai o cara fica no crime", José demonstra que sua opção é pelo lugar da "heterotopia", um lugar de interdito social. Observa-se nessa fala "uma pertença que se afirma pela não pertença". (SANTOS, 1999, p. 3). Ele pertence ao "crime", porque não se considera pertencente a outras esferas da sociedade organizada, como a escolar. O modo como o adolescente se situa em relação à escola e ao "crime" informa as bases da exclusão, em pertencer por não pertencer, expressando um "mundo de vozes sociais em múltiplas relações dialógicas". (FARACO, 2009, p. 84).

A exclusão, compreendida como um fenômeno cultural, sustenta-se na reprodução de uma diversidade de vozes sociais. José toma o discurso social de exclusão como um discurso de verdade em relação a si mesmo. Esse fato demonstra a assimilação da exclusão, motivada por experiências que formam um "conjunto especial de circunstâncias, sentimentos, histórias e experiências únicas e peculiarmente nossas como sujeitos individuais". (HALL, 1997, p. 26). Esse processo de assimilação de discursos sociais pode se constituir por meio de relações dialógicas, fundamentadas em contextos de risco social e nas vivências relativas à exclusão escolar, em vista das dificuldades de integração na escola e das múltiplas reprovações, além da própria vulnerabilidade social, tornando-se possiveis caminhos para o ato infracional.

Assim sendo, o abandono escolar pode ser percebido como resultado de um processo de exclusão, pelo fato de o adolescente se perceber fracassando em sua aprendizagem, gerando um sentimento de não identificação com o meio escolar. Enquanto ele não se identifica com a escola, lugar que o faz se sentir incompetente. a identificação com outros adolescentes em condição semelhante é plena.
A opção de José por ficar no "crime" também retrata a condição de adolescentes que não estudam nem trabalham, os "nem-nem", que vagam pelas ruas da periferia sem perspectiva de inserção social e frequentemente são recrutados por facções criminosas, lideradas por adultos. Embora as vantagens materiais desse recrutamento cruel sejam importantes, é mais significativo aos adolescentes, com carências de diversas ordens, a importância de ser alguém, de se sentir "apoiado", em um forte sentimento de pertencimento. (CRAIDY, 2015).

Ainda cabe observar que o tempo médio entre o abandono escolar até o ingresso na internação para esses adolescentes é de dois anos. 0 maior tempo de abandono foi o de Rafael, que saiu da escola com 10 anos. Na data da geração de dados, estava com 16 anos e comentou que havia deixado a escola. Assim disse Rafael: "eu não tava aprendendo nada, nada, eu bah! Mas, na real, a escola não é pra mim, vô solta de vez e soltei e entrei pra vida do crime".

A reflexão de Rafael demonstra o fenômeno representativo como um produto e um processo de apropriação da realidade exterior ao pensamento e de uma elaboração psicológica e social da realidade (JODELET, 1993, p. 5), pois ele utiliza essa representação para justificar sua escolha de ingressar no "crime". Observamos que seu discurso se organiza com base nos argumentos de que "não tô aprendendo nada/a escola não é pra mim/vô solta de vez", ou a informação de "entrei pra vida do crime" ocorre no discurso como uma alternativa de vida em relação ao processo de experiências subjetivas que vivenciou na escola.

\section{Fenômenos representativos sobre o aprendizado de língua materna}

Dentre o que os adolescentes gostam nas aulas de Lingua Portuguesa, observa-se que ler, escrever, copiar e aprender são ações positivas para eles. Eles não gostam daquilo que não conseguem entender e de responder o que não sabem, conforme se evidencia no quadro a seguir. 
Quadro 2 - Agrupamento de fenômenos representativos relativos ao que os adolescentes gostam e ao que não gostam nas aulas de Língua Portuguesa

Sobre as aulas de Lingua Portuguesa

\begin{tabular}{|c|c|}
\hline O que os alunos gostam & O que os alunos não gostam \\
\hline Mário: copiá (gosto) e lê. & $\begin{array}{l}\text { Mário: não gosto de redação, porque não tenho ideia pra } \\
\text { interpretá um texto, parece que não tenho criatividade. }\end{array}$ \\
\hline Luiz: gosto de aprendê. & Luiz: não gosto do que eu não consigo entender. \\
\hline Pedro: lê e copiá (gosta). & Pedro: responder aquilo que eu não sei. \\
\hline João: texto, eu já gosto de escrevê. & $\begin{array}{l}\text { João: eu não gosto das respostas e das perguntas, eu já } \\
\text { acho complicado. }\end{array}$ \\
\hline $\begin{array}{l}\text { Maria: eu gostava, na época a gente fazia bas- } \\
\text { tante ditongo e hiato; a professora trazia bas- } \\
\text { tante histórias pra gente criá em quadrinho eu } \\
\text { gostava. }\end{array}$ & $\begin{array}{l}\text { José: Dona, no caso, a Sra. sabe. Todo mundo odeia a } \\
\text { aula de português. Pode ter } 30 \text { na sala de aula, ninguém } \\
\text { gosta da aula de português (Porque) é muito cheia de } \\
\text { detalhe. Uma vírgula, um bagulhinho já tá errado, por } \\
\text { isso que eu acho que as pessoas não gostam. Às vezes, } \\
\text { o cara esquece de uma vírgula, bota num lugar e esque- } \\
\text { ce no outro, aí é porque as pessoas não gostam, tem } \\
\text { que escrevê afu, né. }\end{array}$ \\
\hline \multirow[t]{2}{*}{$\begin{array}{l}\text { Joana: eu aprendia muito sobre substantivo ad- } \\
\text { jetivo, ação, era sobre frases de ação, reação } \\
\text { essas coisas. }\end{array}$} & Lucas: eu acho que é porque copia mais. \\
\hline & $\begin{array}{l}\text { Laura: não gosto de português. Tudo o que eu não sei } \\
\text { (eu não gosto). }\end{array}$ \\
\hline $\begin{array}{l}\text { Flávia: eu gostava de estudá, de fazê texto que } \\
\text { nem ela falô de quadrinho. Fazia bastante histó- } \\
\text { ria em quadrinho. }\end{array}$ & \\
\hline
\end{tabular}

Fonte: Bastos (2019, p. 89).

As falas de Mário, Luiz, João e Pedro, postas em paralelo, chamam atenção pelo fato de que ler, escrever e copiar são coisas que eles gostam de fazer. Parece haver, contudo, um sentido de atividade mecânica nessas ações, considerando-se que as atividades que demandam reflexão não lhes são inteligiveis, consequentemente não lhes são apraziveis. Isso também se verifica no excerto de Laura, quando diz: "Não gosto de português. Tudo o que eu não sei (eu não gosto)".

Em meio a esses fenômenos representativos, compreendemos que as aulas de Língua Portuguesa, em essência, são representadas como algo inatingivel aos adolescentes, pois, embora ler e aprender, por exemplo, seja algo de que eles gostam de fazer, ao mesmo tempo, não gostam do que não conseguem entender. Não é possivel ler e aprender sem entender. Sem entendimento, não há sentido, não há significado no aprendizado, nas aulas e muito menos na linguagem.

Ao refletir sobre esses dados, devemos ter em mente o fato de que essas falas pertencem a adolescentes com idades entre 15 e 18 anos, em média, que estão cursando os anos finais do ensino fundamental na modalidade EJA. Esses jovens têm uma acentuada defasagem idade-série e abandonaram a escola há, no mínimo, dois anos, conforme Bastos (2019).

Além disso, os fenômenos representativos desses adolescentes remetem à ideia de Tfouni, Pereira e Assolini (2018, p. 19), que associam o espaço escolar a um país diferente onde a língua 
que se fala e as regras de comportamento são diferentes daquelas com que estão familiarizados. Assim sendo, o "não sei, não entendo, não tenho criatividade" são fenômenos representativos que demonstram um distanciamento entre a realidade do adolescente e o ensino a ele destinado.

Para José, "ninguém gosta da aula de português, porque é muito cheia de detalhe", representando as aulas de Lingua Portuguesa como sendo o espaço do certo e do errado: "uma vírgula, um bagulhinho, já tá errado, por isso eu acho que as pessoas não gostam", afirma José. O aprendizado de língua portuguesa na representação de José não é significativo, "às vezes, o cara esquece de uma virgula, bota num lugar e esquece no outro, ai é porque as pessoas não gostam, tem que escrevê afu, né!". Escrever "afu" significa, na gíria desses adolescentes, escrever muito, em grande quantidade. A percepção de José demonstra a relação dialética entre ensino, aprendizagem e cultura, observados por Oliveira (2010), porque retrata o que era significativo no ato de ensinar no contexto escolar a que pertencia.

Maria percebe as aulas de português de modo diferente, pois recorda positivamente atividades de produção de histórias em quadrinhos, embora também enfatize a nomenclatura gramatical: "eu gostava, na época a gente fazia bastante ditongo e hiato; a professora trazia bastante histórias pra gente criá em quadrinho e eu gostava". Assim como Maria, Flávia afirma: "eu gostava de estudá, de fazê texto que nem ela falô de quadrinho. Fazia bastante história em quadrinho".

Embora Maria e Flávia mencionem o aprendizado de categorias gramaticais, recordam positivamente a atividade de produção de histórias em quadrinhos. É possivel que essa lembrança positiva das adolescentes ocorra em vista de a produção de quadrinhos ter sido significativa, ter produzido essa escrita fez sentido para elas.

Os fenômenos representativos de José, Maria e Flávia indicam duas diferentes culturas (OLIVEIRA, 2010) de ensino e aprendizagem da língua. A primeira, socialmente arraigada, relativa à análise e memorização sistemática de elementos gramaticais. Essa primeira cultura, evidencia- mos nas falas de Maria: "na época a gente fazia bastante ditongo e hiato"; e Joana: "eu aprendia muito sobre substantivo adjetivo, ação, era sobre frases de ação, reação essas coisas". A segunda cultura diz respeito a uma atividade de ordem mais interativa, que é a produção de histórias em quadrinhos. Os letramentos se constituem e são constituidos pela cultura de ensino e aprendizagem das escolas de onde se originaram os adolescentes (OLIVEIRA, 2010).

\section{Considerações finais}

A multiplicidade de significados que ocorrem nos fenômenos representativos dos adolescentes leva-nos a perceber que o que (des)motiva o adolescente ao aprendizado está relacionado ao seu contexto de vulnerabilidade social. Os fatores relacionados à identidade, diferença e in/ exclusão subjazem o ensino de língua materna, não só no contexto de ensino socioeducativo, mas também em todos os outros contextos de ensino mediados pela vulnerabilidade social.

Dessa diversidade de elementos, chama-nos atenção a "naturalização" dos objetos rua, "crime" e dinheiro, evidenciando que os jovens se submetem àquilo que, em sua percepção, pode trazer-lhes algum "retorno" material e emocional, por se sentirem "incluídos". Esses objetos impactam nas concepções de identidade e diferença, de modo que os adolescentes se posicionam na condição de "criminalidade".

Os fenômenos representativos identificados nas falas dos adolescentes nos levam a concluir que esses jovens têm internalizado, sob um processo dialógico, não só o discurso social de exclusão, mas também o da vivência da exclusão, fundamentados na experiência, pelo contexto de desigualdade em que vivem.

Os fenômenos representativos associados à escola demonstram que há uma percepção dos adolescentes de que o espaço escolar não lhes pertence, e o ensino e a aprendizagem, no sentido de conteúdos e linguagens, não são significativos a eles. A frustração com as sucessivas reprovações também é um fator que os desmotiva ao aprendizado e os leva a rejeitar a escola

No que tange ao aprendizado de língua portu- 
guesa, observamos que as atividades de interpretação textual são muito dificeis para esses jovens. Eles afirmam que não entendem as perguntas, consideram-se questionados sobre o que não sabem responder. Afirmam não compreender a linguagem do texto ou da pergunta. Além disso, muitos adolescentes representam as aulas de língua materna como centradas em ler, escrever e copiar.

A inter-relação entre linguagem e educação apresenta potencial para transformar as representações dos mundos de vida dos adolescentes e formar sujeitos críticos, que rejeitem o lugar social no qual foram colocados sem, contudo, romperem com as regras sociais e éticas vigentes. Para além do direito à palavra, observamos que os adolescentes precisam desenvolver a consciência e o sentido de propriedade para expressar sua palavra. Este estudo exploratório possibilitou o planejamento de novos estudos que estão sendo desenvolvidos pelas autoras no contexto da escola participante.

Em vista do exposto, observamos, de modo geral, que o espaço de escolarização em contexto socioeducativo demanda o desenvolvimento de mais estudos. Tais estudos devem voltar-se, não só ao ensino de língua materna, mas também às outras disciplinas curriculares, visando qualificar os processos de ensino e aprendizagem nesse espaço. Finalmente, podemos afirmar que é na escola, inserida no espaço de internação socioeducativa, que muitos jovens têm a oportunidade de aterem-se ao aprendizado e ao seu desenvolvimento pessoal. Desse modo, as vivências escolares nesse espaço podem (re)significar as perspectivas de vida desses jovens.

\section{Referências}

BASTOS, S. C. M. Na escola, o cara tinha que ficá quieto, olhando pro quadro e escrevendo. Na rua, eu fazia o que eu queria": Fenômenos representativos de adolescentes em conflito com a lei sobre as aulas de língua materna, escolarização e abandono escolar. 2019. 10of. Dissertação (Mestrado em Linguística Aplicada) - Programa de Pós-Graduação em Linguística Aplicada, Universidade do Vale do Rio dos Sinos (UNISINOS), São Leopoldo, 2019.

BISINOTO, Cynthia et al. Socioeducação: origem, significado e implicações para o atendimento socioeducativo. Psicologia em Estudo. Maringá, v. 20, n. 4. p. 575-585, out./ dez. 2015. https://doi.org/10.4025/psicolestud.v20i4.28456.
BOZZA, Morgana. Os sentidos da "escola inserida" para os jovens privados de liberdade: cada dia é um dia. In: STECANELA, Nilda (org.). Ler e escrever a vida: trajetórias de jovens em privação de liberdade. Caxias do Sul: Educs, 2012. p. 93-115.

BRASIL. Lei $n^{\circ} 12594$, de 18 de janeiro de 2012. Institui o Sistema Nacional de Atendimento Socioeducativo (Sinase). Brasilia, DF: Presidência da República, 2012. Disponivel em: http://www.planalto.gov.br/ccivil_03/_ato20112014/2012/lei/l12594.htm. Acesso em: 17 nov. 2019.

BRASIL. Lei no 8069, de 1990. Dispõe sobre o Estatuto da Criança e do Adolescente e dá outras providências. Brasilia, DF: Presidência da República, 1990. Disponivel em: http://www.planalto.gov.br/ccivil_03/leis/l8069. htm. Acesso em: 17 nov. 2019.

CELANI, Maria Antonieta Alba. Afinal, o que é Linguistica Aplicada. In: PASCHOAL, Mara Sofia Z de; CELANI, Maria Antonieta Alba (org.). Linguistica Aplicada: da aplicação da linguística à linguística transdisciplinar. São Paulo: EDUC-PUCSP, 1992. p. 15-23.

COMERLATO, Denise. Letramento, Alfabetização e Vulnerabilidade Social. In: CRAIDY, Carmen Maria; SZUCHMAN, Karine (org.). Socioeducação: fundamentos e práticas. Porto Alegre: Evangraf, 2015. p. 90-95.

CRAIDY, Carmen Maria. Medidas socioeducativas e direitos: o paradigma do jovem infrator como sujeito de direitos. In: STECANELA, Nilda (org.). Ler e escrever a vida: trajetórias de jovens em privação de liberdade. Caxias do Sul: Educs, 2012. p. 47-60.

CRAIDY, Carmen Maria; SZUCHMAN, Karine (org.) Socioeducação: fundamentos e práticas. Porto Alegre: Evangraf, 2015

FARACO, Carlos Alberto. Linguagem \& diálogo: as ideias linguísticas do círculo de Bakhtin. São Paulo: Parábola, 2009.

FLICK, Uwe. Introdução à pesquisa Qualitativa. Tradução: Joice Elias Costa. 3. ed. São Paulo: Artmed, 2009.

FLORES, Valdir do Nascimento et al. Dicionário de Linguistica da Enunciação. São Paulo: Contexto, 2009. 284 p.

GASKELL, G. Entrevistas individuais e grupais. In: BAUER, Martin W.; GASKELL, George (org.). Pesquisa qualitativa com texto, imagem e som: um manual prático. 10. ed. Petrópolis: Vozes, 2012. p. 64-89.

HALL, Stuart. A identidade cultural na pós-modernidade. Rio de Janeiro: DP\&A, 2006.

HALL, Stuart. A centralidade da cultura: notas sobre as revoluções culturais do nosso tempo. Educação e Realidade, Porto Alegre, v. 2, n. 22, p. 15-46, 1997. Disponivel em: http://seer.ufrgs.br/index.php/educacaoerealidade/article/view/71361. Acesso em: 20 mar. 2018.

HALL, Stuart. A identidade cultural na pós-modernidade. Rio de Janeiro: DP\&A, 2006.

JODELET, Denise. A representação: noção transversal, ferramenta da transdisciplinaridade. Tradução: Lia Obojes. Cadernos de Pesquisa, [s. l.], v. 46, n. 162, p.1258-1271, out./dez. 2016. Disponivel em: http://WWW.scielo.br/pdf/cp/V46n162/1980-5314cp-46-162-01258.pdf. Acesso em: 10 nov. 2018. https:// doi.org/10.1590/198053143845. 
JODELET, Denise. Ciências sociais e representações: estudo dos fenômenos representativos e processos sociais, do local ao global. Tradução: José Geraldo de Oliveira Almeida. Revista Sociedade e Estado, [s. l.], v. 22, n. 2, p. 423-442, maio/ago. 2018. https://doi. org/10.1590/s0102-699220183302007.

JODELET, Denise. Representações Sociais e Mundos de Vida. Tradução: Lilian Ulup. Edição: Nikos Kalampalikis. São Paulo: Fundação Carlos Chagas; Curitiba: PUCPRess, 2017

JODELET, Denise. Représentations sociales: um domaine em expansion. In: JODELET, D. (org.). Les Représentations sociales. Paris: PUF, 1989. p. 31-61. Tradução: Tarso Bonillha Mazzotti. Revisão Técnica: Alda Judith Alves-Mazzotti. UFRJ - Faculdade de Educação, dez. 1993. Uso escolar, proibida a reprodução.

OLIVEIRA, Maria do Socorro. Variação cultural e ensino/ aprendizagem de lingua materna: projetos de letramento em comunidade de aprendizagem. In: VÓVIO, Cláudia; SiTIO, Luanda; GRANDE, Paula de (org.) Letramentos: rupturas, deslocamentos e repercussões de pesquisa em Linguística Aplicada. Campinas: Mercado das Letras, 2010.

PAIVA, Vera Lúcia Menezes de Oliveira. Manual da Pesquisa em Estudos Linguisticos. São Paulo: Parábola, 2019.

PADOVANI, Andréa Sandoval; RISTUM, Marilena. Significados Construidos acerca das Instituições Socioeducativas: Entre o Imaginado e o Vivido. Psico-USF, [s. L.],. v. 21, n. 3, p. 609-622, set. 2016. https://doi.org/10.1590/1413$\underline{82712016210314}$

PESSOA E SILVA, Maria Denise et al. Saúde Mental e Fatores de Risco e Proteção: Focalizando Adolescentes Cumprindo Medidas Socioeducativas. Revista Brasileira de Crescimento e Desenvolvimento Humano, [s. L.], v. 25, n. 2, p. 1-8, jul. 2015

SANTOS, Boaventura de Souza. A construção da igualdade e da diferença. Oficina. CES n 135 . Rio de Janeiro, 1999. Disponivel em: www.ces.uc.pt/publicacoes/ oficina/ficheiros/135.pdf. Acesso em: 31 mar. 2018.

SILVA, Tomaz Tadeu da. A produção social da identidade e da diferença. In: SILVA, Tomaz Tadeu; HALL, Stuart; WOODWARD, Kathryn. Identidade e diferença: a perspectiva dos estudos culturais. Petrópolis Vozes, 2000. p. 73-102.

SILVERMAN, David. Interpretação de dados qualitativos Tradução: Magda França Lopes. Porto Alegre: Artmed, 2009.

SINASE, Sistema Nacional de Atendimento Socioeducativo. Secretaria Especial dos Direitos Humanos. Brasilia, DF: CONANDA, 2006

SOUZA, Tatiana Yokoy de; OLIVEIRA, Maria Cláudia Santos Lopes de. O contexto das medidas socioeducativas: promoção da paz ou valores da cadeia. In: BRANCO, Angela Maria Uchoa de Abreu; OLIVEIRA, Maria Cláudia Santos Lopes de (org.). Diversidade e cultura da paz na escola: contribuições da perspectiva sociocultural. Porto Alegre: Mediação, 2012. p. 291-309.
SPINK, Mary Jane. Desvendando as teorias implícitas: uma metodologia de análise das representações sociais. In: GUARESCHI, Pedrinho; JOVCHELOVITCH, Sandra (org.). Textos em Representações Sociais. Petrópolis: Vozes, 2013. p. 95-118.

STECANELA, Nilda. Jovens e Cotidiano: trânsito pelas culturas juvenis e pela "escola da vida". 2008. 397f. Tese (Doutorado em Educação) - Universidade Federal do Rio Grande do Sul, Porto Alegre, 2008.

TFOUNI, Leda Verdiani; PEREIRA, Anderson de Carvalho; ASSOLINI, Filomena Elaine Paiva. Letramento e Alfabetização e o Cotidiano: vozes dispersas, caminhos alternativos. Calidoscópio, [s. l.], v. 16, n. 1, p. 16-24, jan./ abr. 2018. https://doi.org/10.4013/cld.2018.161.02.

VOLPI, Mário. Educação em direitos humanos na socioeducação. In: MENEZES, Magali M. de et al (org.). Direitos humanos em debate: educação e marcadores sociais da diferença. Porto Alegre: Cirkula, 2019. p. 195-203.

\section{Sabrina Cecillia Moraes Bastos:}

Doutoranda em Linguística Aplicada pelo Programa de Pós-Graduação em Linguistica Aplicada da Unisinos. Mestre em Linguística Aplicada pela Universidade do Vale dos Sinos (Unisinos) (2019).

Linha de Pesquisa Linguagem e Práticas Escolares, com foco em linguagem e inclusão.

Graduada em Letras, Uniritter (2007), especializações lato-sensu em Assessoria Linguística, Uniritter (2009), e em Ensino de Gramática da Língua Portuguesa, FAPA (2013).

Professora de Língua Portuguesa na Rede Pública Estadual do Rio Grande do Sul.

\section{Cátia de Azevedo Fronza}

Possui graduação em Letras Português-Inglês, pela Fundação Educacional da Região dos Vinhedos (1991), Mestrado em Letras (1994) e Doutorado em Letras (1999), pela Pontificia Universidade Católica do Rio Grande do Sul, com área de concentração em Linguística Aplicada. Realizou Estágio Sênior, com apoio da CAPES (Processo n. 002747/2015-04), na Universidade de Goningen, Holanda, sob supervisão da Profa. Dra. Marjon Tammenga-Helmantel (Faculty of Behavioural and Social Sciences - Univeristy of Groningen). É docente do Curso de Letras e do Programa de Pós-Graduação em Linguística Aplicada da Universidade do Vale do Rio dos Sinos. É líder do Grupo de Pesquisa "Aquisição e desenvolvimento da linguagem: relações entre fala e escrita", cadastrado no Diretório de Grupos de Pesquisa do CNPq. Tem experiência na área de Linguistica, com ênfase em aquisição da linguagem, aquisição da fonologia, atuando principalmente nos seguintes temas: aquisição da fala, aquisição/aprendizagem da escrita e implicações desses processos no ensino e na aprendizagem de línguas, considerando a educação de surdos e especificidades linguisticas no âmbito da educação inclusiva. 